\title{
Barriers and Opportunities for Sanitation and Water for All, as Envisaged by the New Delhi Statement
}

\author{
Jon Lane
}

Abstract Today, 884 million people lack access to water and 2.6 billion lack access to sanitation. In the past 20 years, there has been important progress made in these areas at the international level. But despite some milestones, significant challenges remain to be addressed. Some of these milestones reflect recommendations from the New Delhi Statement, which endorsed the principle of 'Some for All Rather than More for Some', and its four guiding principles, ${ }^{1}$ as do some of the remaining challenges. Other trends have emerged since then, as well. This article identifies the main political developments over the last 30 years and examines some barriers to the progress of attaining universal water and sanitation provision. It also outlines some of what we have done or not done in implementing the concepts contained in the New Delhi Statement, and identifies some key lessons for the future.

\section{Introduction}

At the close of the International Drinking Water Supply and Sanitation Decade (1981-90), the General Assembly of the United Nations passed a resolution to complete the work left unfinished and formally recognised the Water Supply and Sanitation Collaborative Council (WSSCG) as a contributor to finishing this work. The Decade aimed to make access to clean drinking water and safe sanitation available for everyone in the world by 1990 . Notably, work by a variety of engaged stakeholders, from governments to nongovernmental organisations (NGOs), did in fact bring water supply services to over 1.2 billion people and safe sanitation to almost 770 million during the ten years. But this was not enough to keep up with rapid growth and urbanisation in developing countries, and today there are still almost 900 million people who have inadequate access to drinking water and nearly three times as many, 2.6 billion, without appropriate sanitation.

When WSSCG was founded at the Global Consultation on Safe Water and Sanitation held in New Delhi in September 1990, it and many others working with water supply and sanitation still had a long way to go to achieve universal coverage. Since then, there has been significant progress made reaching the under-served and unserved populations in water and sanitation throughout the world. However, there are still too many people who lack access to safe water and sanitation. Figure 1 shows where the world was and is in terms of access to improved water and sanitation worldwide.

In terms of water, the world is slightly better off - the number of people without access to water is fewer than it was 20 years ago as progress has been made relative to population growth. However, sanitation coverage is not doing as well. Two and a half billion people lacked sanitation in 1990, about the same number who do not have access to sanitation now. Progress in sanitation over 20 years has not closed that gap, managing only to keep pace with population growth. The UN 2002 World Summit on Sustainable Development, the United Nations Development Programme (UNDP) Human Development Report of 2006, and the United Nations HighLevel Event on the Millennium Development Goals (MDGs) in 2008 concluded that the target for water supply is achievable, but targets for sanitation will not be met by 2015 (Rosemarin $e t$ al. 2008). Despite 1.3 billion having gained access to improved sanitation since 1990, the world will

IDS Bulletin Volume 43 Number 2 March 2012 (c) 2012 The Author. IDS Bulletin (c) 2012 Institute of Development Studies Published by Blackwell Publishing Ltd, 9600 Garsington Road, Oxford OX4 2DQ, UK and 350 Main Street, Malden, MA 02148, USA 


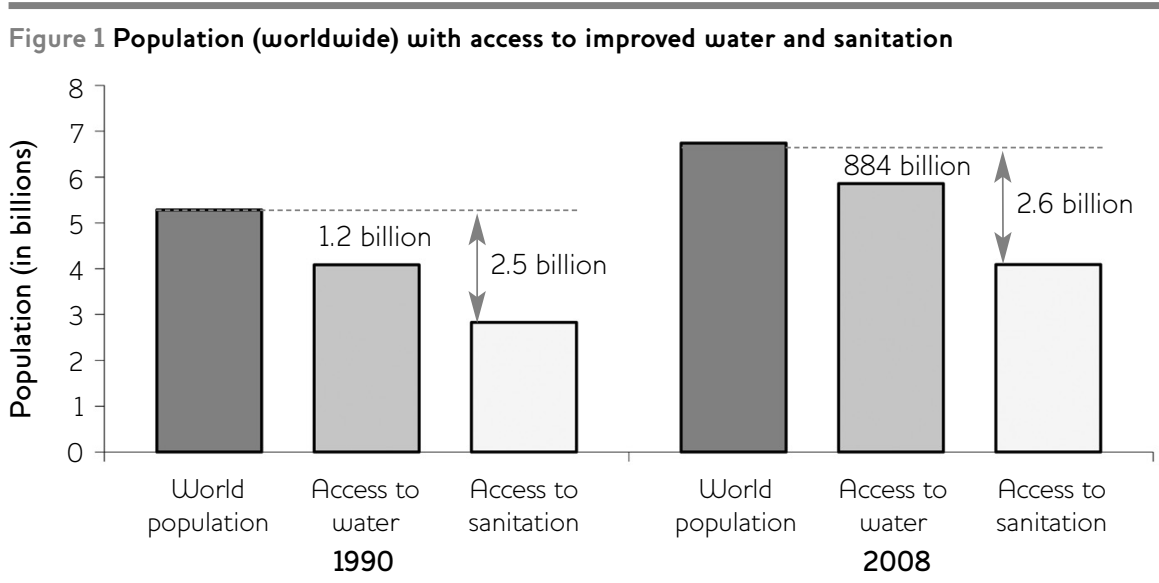

Source WHO/UNICEF Joint Monitoring Programme (JMP) for Water Supply and Sanitation, www.wssinfo.org/

still miss the sanitation MDG target of 2015 by a billion people (WHO/UNICEF JMP 2010).

Since its inception, WSSCG aims to achieve sustainable water supply, sanitation and hygiene for all people in the world and works alongside many other organisations towards this end. In recent years, WSSCG's strategy has been to focus more on sanitation and hygiene. In the context of the New Delhi Statement principles, here are some important trends which we have noticed especially in the last five years:

- Historically, sanitation and hygiene have been neglected and underfunded topics characterised by inconsistent approaches and policies, fragmentation and unclear responsibilities. In recent years this has started to change: the United Nations have formally recognised access to safe drinking water and sanitation as a human right, more organisations have become engaged in sanitation and hygiene, and new networks and initiatives have started. Media and political decision-makers are beginning to understand the huge benefits of improved sanitation. Seen from the Delhi perspective, there is good momentum behind community management of services.

- Political leaders have recognised that sanitation is different from water in aims, timescales and skills needed, and in country after country we see a specified ministry responsible for sanitation with a sanitation and hygiene policy and budget. As Delhi suggested, institutional reforms and changes in procedures were necessary, and this is starting to happen.
- Decision-makers have realised that centralised waterborne sewerage is economically and environmentally untenable for the vast majority of people around the world. So sanitation policy nowadays acknowledges onsite sanitation as most viable for rural areas and even for low-density urban populations. Again, Delhi suggested 'sound financial practices', and these trends, at least for sanitation, are of the economical and environmentally tenable type.

- Until recently, most sanitation policies - if they existed at all - were based on subsidising the cost of latrines or toilets, i.e. building toilets for people whether they wanted them or not. Across the developing world about half of those toilets are used for their intended purpose, while half serve as store rooms for food, bicycles and other valued possessions. So now many countries' and agencies' policies have moved on to emphasise hygiene promotion and demand creation. Delhi suggested approaches are needed which are integrated, both to protect environment and health, as hygiene promotion activities do.

The above are some examples of what has been seen particularly for sanitation in recent years. The rest of this article will explore some of the key milestones since 1990 and the major policy trends in sanitation and water during the past 20 years, followed by lessons that have emerged, and five points for looking ahead.

\section{Brief overview of select milestones since New Delhi - the past 20 years}

While there have been many important events since 1990, this article will highlight only some of these to show the progression of the sector. 
Figure 2 VISION 21: A shared vision for hygiene, sanitation and water supply and a framework for action

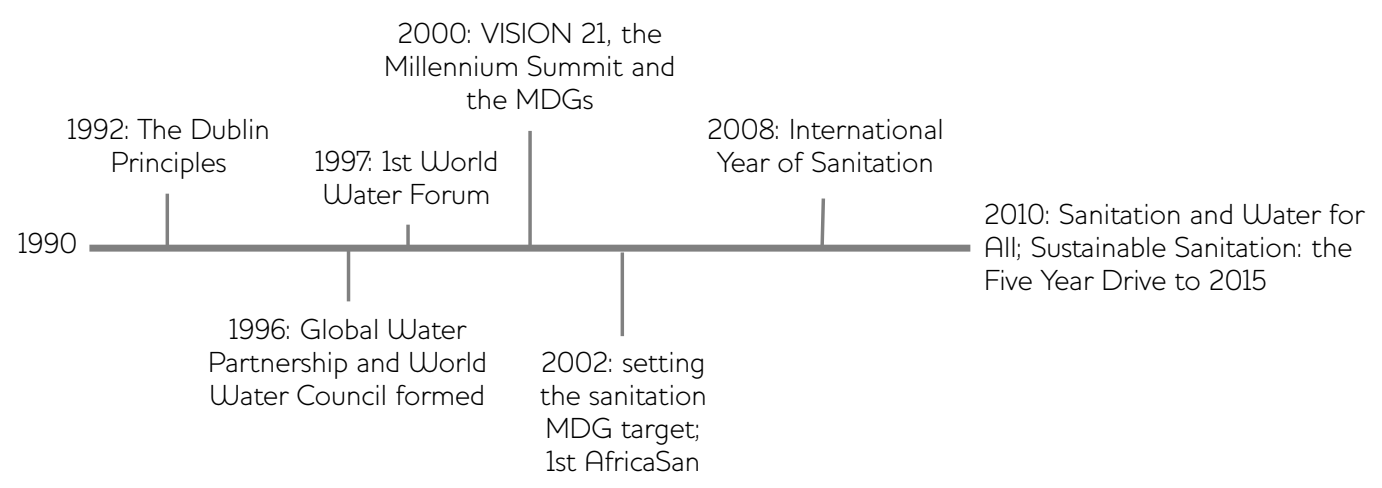

Source WSSCC (2000).

\subsection{Pre-MDGs: $1990-9$}

1992

The International Conference on Water and the Environment held in Dublin, Ireland, in January 1992 yielded the Dublin Statement on Water and Sustainable Development (also known as the Dublin Principles). The four Dublin Principles recognised the increasing scarcity of water. Out of the four principles, the greatest focus has been on the principle that talks about water as an economic good, and there has been considerable misunderstanding about what the concept of water as an economic good implies (Savenije and van der Zaag 2002). This somewhat eclipsed the progress made at New Delhi two years prior.

\section{6}

Both the Global Water Partnership (GWP) and the World Water Council, two global organisations driven forward with World Bank support, were founded in 1996. The GWP continues to offer practical advice for managing water resources in a sustainable manner while the World Water Council organises the World Water Forum.

\section{7}

The first World Water Forum was held 20-22 March 1997 in Marrakech, Morocco. It was at this event that World Water Vision, a shared vision on world water for the long term, was introduced.

The World Water Forum, organised every three years (the sixth to be held in 2012), has become the largest international event on water. It has raised awareness on water issues and generating action; provided a platform for developing shared visions on water issues and cooperation among various stakeholders; and attracted media attention for water issues and solutions.

\subsection{UN Millennium Summit and the MDGs} 2000

By 2000, significant progress was being made in the water and sanitation sectors. WSSCG created a long-term strategy document, VISION 21, on universal access to water and sanitation and the strategies to attain it. VISION 21 was launched at the second World Water Forum, held 16-22 March 2000 in The Hague, Netherlands. This initiative outlined a conceptual framework through an examination of the core issues in water and sanitation and delineated a route to fulfilling VISION 21.

Later that year, in September, the UN Millennium Summit was held to discuss the role of the UN at the turn of the twenty-first century. World leaders ratified the Millennium Declaration, from which the MDGs are derived. The MDGs have since become quite dominant in our thinking about water and sanitation issues, particularly amongst politicians and leading practitioners, and have somewhat overshadowed other work around that time.

\section{2}

Many people often forget that sanitation was not a part of the MDGs originally and that it was inserted later (Rosemarin et al. 2008) as part of MDG 7 on environmental sustainability. The sanitation MDG target was established at the World Summit on Sustainable Development held 
in Johannesburg, in August-September 2002. WSSCG was at the forefront, leading on putting the political pressure to have the sanitation target achieved.

Since the MDGs are so prominent, the goal to halve the number of people without water and sanitation has been the major focus of efforts in the area.

\subsection{Water and sanitation organisations and conferences}

In the early 2000s, WSSCG helped to establish regional sanitation conferences in order to place specific focus on issues in particular areas. As a result, the first African Conference on Hygiene and Sanitation (AfricaSan) was held 29 July1 August 2002 in Gauteng, South Africa, as part of the campaign leading to the establishment of the sanitation MDG target. Now, regional sanitation conferences take place regularly in Africa (AfricaSan), South Asia (SACOSAN), East Asia (EastAsiaSan), and Latin America (LatinoSan) the regions that bear the highest burden of people living without sanitation. These regional conferences encourage cross-regional dialogue and spur political action as they offer a platform for practitioners and policymakers to get together and make progress on substantive issues.

Other notable platforms for discussions around water and sanitation include the Stockholm Water Symposium (now called World Water Week in Stockholm), initiated in 1991, the African Ministerial Conference on Water (AMCOW) in 2002, UN-Water (an umbrella mechanism which coordinates water-related activities of UN organisations and partners), endorsed in 2003, and the UN SecretaryGeneral's Advisory Board on Water and Sanitation (UNSGAB), created in 2004.

\subsection{Most recent high-profile efforts 2008}

In the past few years, it has become evident that the progress towards achieving the sanitation MDG has been slow and varied throughout the world. To help get this MDG back on track, the International Year of Sanitation (IYS) was declared in 2008. IYS gave the sector a real boost in terms of the political profile of sanitation which, until then, had been very badly neglected. Deemed a successful global advocacy and communications campaign, IYS communicated that access to basic sanitation improves health, generates economic development, promotes social development, helps the environment, and is universally achievable (Lane 2008).

\section{0}

Sanitation and Water for All (SWA), established in 2010, aims to achieve collective action among developing country governments and donor governments, along with multilateral agencies, civil society and other development partners. SWA had its first high-level meeting of finance ministers and international development ministers in April 2010.

And finally, Sustainable Sanitation: the Five Year Drive to 2015, initiated by UNSGAB and adopted by the General Assembly of the United Nations on 20 December 2010, will help to keep the momentum of the IYS going. This new initiative also aims to boost efforts in closing the sanitation gap.

\section{Major policy trends during the past 20 years}

As the previous section outlined, there have been many events held and organisations formed to further efforts towards universal access to water and sanitation. Over the past 20 years, several policy trends became particularly prominent, namely Integrated Water Resources Management, water privatisation, differences between water and sanitation, the human rights debate, and the MDGs.

\subsection{Integrated Water Resources Management - what does it mean?}

Inspired by the four Dublin Principles, Integrated Water Resources Management (IWRM) has been one of the big phrases in the past 20 years. The definition of IWRM is encompassing: 'a process which promoted the coordinated development and management of water, land and related resources in order to maximise economic and social welfare in an equitable manner without compromising the sustainability of vital ecosystems and the environment' (GWP 2011).

The sector has been very enthusiastic about IWRM, though there has been some muted criticism that the concept lacks some precision. On the surface, IWRM as a concept looks attractive while deeper analysis reveals various issues, particularly in operationalisation (Biswas 
2004). Evidence for the success of IWRM is mixed and there are criticisms for its failure to provide promised benefits (Medema et al. 2008).

There are many obstacles for IWRM to overcome before it can be succesfully implemented. For example, key players need to forge agreements on fundamental issues such as what aspects should be integrated, how, and by whom (Biswas 2004). If sector practitioners continue to laud IWRM as a way forward, it may be more important to move beyond what appears to be a good idea on paper and focus on those concepts that are more practical.

\subsection{The rise and fall of water privatisation}

Despite initial enthusiasm for water privatisation, the sector has moved on. By and large, water privatisation has failed to serve those populations most in need of water and sanitation services. Water privatisation was vigorously promoted in the policy arena and implemented in several countries in the South in the 1990s, yet it has achieved neither the scale nor benefits anticipated (Budds and McGranahan 2003). There are many case studies showcasing the failures of water privatisation (Public Citizen/Water for All 2003). In many cases, the promise that the private sector can bring much-needed financing and ensure access to water and sanitation for those who lack it has not materialised.

The early 2000s saw the retreat of investment in water by transnational corporations due to national economic crises, social protest and the difficulties of extracting profit delivering water to indigent consumers (Robbins 2003). Water privatisation has since retreated to the background as practitioners and decision-makers look for other solutions to the provision of water services and sanitation.

3.3 Recognition that sanitation is different from water Issues in water and sanitation go hand in hand in the global discourse. However, there is now greater recognition that issues surrounding sanitation are different than those regarding water and require different approaches.

Twenty years ago, practitioners did not see the difference between sanitation and water. Now, many governments, particularly in sub-Saharan Africa and South Asia, understand that sanitation is significantly different from water and therefore, it needs a different ministry, a different national policy and a different budget line. This will allow for more targeted approaches and solutions to address sanitation issues.

\subsection{The human rights debate}

On 28 July 2010, the General Assembly of the United Nations declared 'the right to safe and clean drinking water and sanitation as a universal human right'. The General Assembly also called for scaled-up efforts to ensure water and sanitation for all. Further, on 30 September 2010, the UN Human Rights Council adopted the resolution (A/HRC/15/L.14) affirming that access to safe drinking water and sanitation is a human right. With this declaration, the human rights discussion is fully integrated, representing a major milestone in the human rights debate.

\subsection{Concentration on the MDGs}

One of the greatest accomplishments of the MDGs is they have helped concentrate politicians' minds on specific goals in sanitation. However, the pursuit of the target to 'halve, by 2015 , the proportion of the population without sustainable access to safe drinking water and basic sanitation', has led to number chasing. The emphasis of the MDGs on focusing on the indicators rather than the process and direction of development has led to hasty, often top-down approaches that ultimately fail because they do not take people's actual needs into consideration (Movik and Mehta 2009).

Ultimately, the people that get served are the rich and the easy to reach. Characterising the MDGs as a 'common vision' may lead to neglecting people living in extreme poverty (Attaran 2005). Further, thinking of the MDGs as merely exhortatory may be discriminatory against the very poor (ibid.).

\section{Key lessons}

Despite all the work done and the milestones achieved in the past 20 years, water is still not as prominent as it should be in the global political discourse, and sanitation even less so. Below, some of these lessons are explored.

\subsection{Understanding the negative effect of concentrating on the MDGs}

The overemphasis on the MDGs targets has led to some negative effects given that the difficultto-reach and poorest populations may be 
neglected. So the concept of the MDG being a reduction by half is actually counterproductive when looking at issues of equity and inclusion, and of service to those people who are most in need. A means-based approach rather than the current MDG ends-based targets may be more helpful in attaching universal access.

In Europe, Japan, and North Amerca, it took $40-50$ years of effort in the industrial age to halve the number of people unserved in sanitation. Sanitation professionals should not be too preachy towards developing countries and say they are going too slowly, because the histories of Europe and North America were even slower in this regard.

\subsection{Working with politicians to achieve progress}

One of the most important lessons is that things tend to get done when it is high on a politician's agenda. Moe and Rheingans (2006) found that there are four universal barriers to progress in water and sanitation access: (1) inadequate investment in infrastructure; (2) lack of political will to tackle tough problems; (3) tendency to avoid new approaches; and (4) failure to follow up on interventions to determine if they are successful and sustainable.

It is vital for the water and sanitation sectors to connect with politicians in order to achieve progress. Practitioners of the sector have the expertise and knowledge to help politicians understand the key messages, and politicians can put these issues on the political agenda. This will ensure the necessary resources for safe water and sanitation.

\subsection{Personality clashes tend to underlie many of the sector's institutional problems}

Twenty years ago, when there were many different organisations seeking solutions to water scarcity and sanitation issues, there was competition for resources and to make themselves heard. Now, especially in developing countries, leadership crosses both water and sanitation sectors, resulting in greater harmony. Armed with common aims and cooperation among practitioners, greater progress can be made.

\subsection{The role of conferences and meetings in creating a common vision \\ Despite criticisms about conferences, they actually have a positive effect in achieving a sense of common purpose. Practitioners,}

particularly those from developing country governments and developing country NGOs, get enormous benefit from attending them.

In making this point, The Girl in the Café (2005) is commendable in providing a glimpse as to how international conferences work. The film showcases a G8 Summit where the protagonist works to help persuade those at the summit over issues of third world debt and poverty in Africa. Positive reviews of the film have pointed to its attempt to try to humanise these complex problems as well as showing the inner workings of international conferences. In using the G8 Summit as a platform, the protagonist was able to create a common vision and achieve progress.

\subsection{Spreading good ideas quickly and clearly}

The key to progress is to continue spreading good ideas quickly and clearly. Community-led Total Sanitation (CLTS) is a good example of this, given the spread and adaptation of this promising approach in various countries in South Asia, sub-Saharan Africa, and Latin America (see Kar, this IDS Bulletin). CLTS is an innovative way to achieve communities free from open defecation. It changes people's behaviour by shifting mindsets - to focus their desire for, and triggering them to build latrines themselves, to use them, and to sustain them.

CLTS was pioneered by Kamal Kar in 2000 in Bangladesh and has spread to more than 40 countries. It gained international recognition relatively quickly, starting with becoming a major focus in SACOSAN 1, with subsequent workshops organised by various NGOs and multilateral organisations helping to raise its profile, and the dissemination of Kamal Kar's papers, and presentations at conferences and meetings helped to create a bandwagon effect (Deak 2008).

According to Kar, 'CLTS has become the basis of the national sanitation strategy of at least seven countries. Roughly 20 million people across the world have been benefiting from CLTS' (Tigno 2011).

\section{Conclusion and five points for looking ahead}

Since the Global Consultation on Safe Water and Sanitation in New Delhi in 1990, important achievements have been made in attaining universal access to water and sanitation. Organisations, conferences and events have been 
formed to harness cooperation among practitioners in the water and sanitation sectors. Water and sanitation is now recognised as a fundamental human right.

The MDGs have both stimulated and hampered progress towards the ultimate goal of universal access to water and sanitation. While they have helped focus attention on the key issues, the MDGs have led to too much focus on chasing numbers rather than ensuring the most in need populations are being served. Further, the sector itself has done a relatively poor job of working with politicians to ensure that water and sanitation issues are more prominent in the global political discourse.

That said, the past 20 years have also seen personality clashes give way to greater cooperation among practitioners, the role of conferences in providing practitioners opportunities to collaborate, and the speedy dissemination of good ideas like CLTS.

As we near the deadline of 2015 for the MDGs, we will need to reassess the still very wide gap to achieving the water and sanitation targets and determine future actions in order to help those

\section{Note}

1 (1) Protection of the environment and safeguarding health through the integrated management of water resources and liquid and solid wastes; (2) Institutional reforms promoting an integrated approach and including changes in procedures, attitudes and behaviour, and the full participation of women

\section{References}

Attaran, A. (2005) 'An Immeasurable Crisis? A Criticism of the Millennium Development Goals and Why they Cannot be Measured', PloS Med 2.10: e318

Biswas, A.K. (2004) 'Integrated Water Resources Management: A Reassessment', Water International 29.2: 248-56

Budds, J. and McGranahan, G. (2003) 'Are the Debates on Water Privatization Missing the Point? Experiences from Africa, Asia and Latin America', Environment and Urbanization 15.2: 87-113

Deak, A. (2008) Taking Community-Led Total Sanitation to Scale: Movement, Spread and Adaptation, IDS Working Paper 298, Brighton: IDS who are most in need of access to water and sanitation.

Looking beyond 2015, five key points need to be put in focus:

i Agreement on the post-MDG targets for water and sanitation will be very important in continuing the momentum of good work and for putting in place a comprehensive plan of action.

ii The importance of equity and the rights-based approach so that no one gets left behind.

iii Making messages to politicians and decisionmakers more effective will help to achieve tangible results, which will be especially important in changing current practices as well as receiving the appropriate support and funding.

iv Moving from the traditional, grant-based aid approach to one focused on broader, societal, economic and social progress to achieve universal sanitation.

v Urban sanitation will be incredibly difficult to tackle. There needs to be recognition that urban sanitation will have different challenges than water and rural sanitation and will need to be addressed accordingly.

at all levels in sector institutions;

(3) Community management of services, backed by measures to strengthen local institutions in implementing and sustaining water and sanitation programmes; and (4) Sound financial practices, achieved through better management of existing assets and widespread use of appropriate technologies.

The Girl in the Café (2005) television film, BBC Wales, distributed by the British Broadcasting Corporation, UK

GWP (Global Water Partnership) (2011) www.gwp.org/en/The-Challenge/What-isIWRM/ (accessed 9 May 2011)

Lane, J. (2008) 'The Great Promise of the International Year of Sanitation', Waterlines 27.4: 323-31

Medema, W.; McIntosh, B.S. and Jeffrey, P.J. (2008) 'From Premise to Practice: A Critical Assessment of Integrated Water Resources Management and Adaptive Management Approaches in the Water Sector', Ecology and Society 13.2: 29 
Moe, G.L. and Rheingans, R.D. (2006) 'Global Challenges in Water, Sanitation and Health', Journal of Water and Health 4: 41-57

Movik, S. and Mehta, L. (2009) Going with the Flow? Directions of Innovation in the Water and Sanitation Domain, STEPS Working Paper 29, Brighton: STEPS Centre

Public Citizen/Water for All (2003) Water Privatization Fiascos: Broken Promises and Social Turmoil, Washington DC: Public Citizen/Water for All

Robbins, P.T. (2003) 'Transnational Corporations and the Discourse of Water Privatization', Journal of International Development 15.8: 1073-82 Rosemarin, A.; Ekane, N.; Caldwell, I.;

Kvarnström, E.; McConville, J.; Ruben, C. and Fogde, M. (2008) Pathways for Sustainable Sanitation - Achieving the Millennium Development Goals, London: IWA Publishing Alliance

Savenije, H.H.G. and van der Zaag, P. (2002)

'Water as an Economic Good and Demand Management', Water International 27.1: 98-104
Tigno, C. (2011) 'Water Ghampion: Kamal Kar. Community-Led Total Sanitation', Water for All News, April, Asian Development Bank (ADB)

UNDP (2006) Beyond Scarcity: Power, Poverty and the Global Water Crisis, Human Development Report, New York: United Nations Development Programme

WHO/UNICEF Joint Monitoring Programme for Water Supply and Sanitation (2010) Progress on Sanitation and Drinking Water: 2010 Update, Geneva: WHO Press

WSSCC (2000) VISION 21: A Shared Vision for Hygiene, Sanitation and Water Supply and a Framework for Action, Geneva: Water Supply and Sanitation Collaborative Council, www.wsscc.org/resources/resource-publications/ vision-21-shared-vision-hygiene-sanitation-andwater-supply-and (accessed 13 January 2012) 